\title{
Pulmonary Abnormalities in Intermediate
}

\section{Alpha-1-Antitrypsin Deficiency}

\author{
William J. Hall, Richard W. Hyde, Robert H. Schwartz, Govind S. Mudholkar \\ D. Robert Webb, Y. P. Chaubey, and Phillip L. Townes
}

From the Departments of Medicine, Pediatrics, Statistics, Radiation Biology and Biophysics, University of Rochester School of Medicine and Dentistry, Rochester, New York 14642

\begin{abstract}
A B S T RAC T Pulmonary function studies were carried out in a group of asymptomatic nonsmoking adults with intermediate alpha-1-antitrypsin deficiency who were attending an early disease detection unit in Rochester, N. Y. All subjects were identified by specific protease inhibitor ( $\mathrm{Pi})$ typing. Fifteen MZ and 14 MS subjects who had never smoked cigarettes were matched by sex and age to $M M$ controls. Spirometry, static lung volumes, and single breath-diffusing capacity were identical in all $\mathrm{Pi}$ type groups with no statistically significant differences noted. Maximal expiratory flow volume curves were obtained in all subjects. MZ subjects demonstrated statistically significant impaired maximal flow rates at $75 \%, 50 \%$, and $25 \%$ of vital capacity compared to their $M M$ controls. Total pulmonary resistance by the oscillometric method was measured at $3,5,7$, and 9 cycle/s in the same subjects. Increased frequency dependence of resistance (defined as the difference between total pulmonary resistance at 3 cycle/s and 9 cycle/s) was observed in $M Z$ subjects compared to $M M$ controls. No differences were noted by this method in $M S-M M$ pairs. The data suggest that detectable mechanical abnormalities are present in subjects with the $M Z$ phenotype, even in the absence of established risk factors such as cigarette smoking and high air pollution.
\end{abstract}

This work was presented in part at the annual meeting of the American Federation for Clinical Research, Atlantic City, N. J., April 28, 1973. A preliminary report has appeared in abstract form. (Hall, W. J., R. W. Hyde, R. Schwartz, D. Webb, and M. Schoenwald. 1973. Quantification of small airway disease in heterozygotes for serum alpha-1-antitrypsin deficiency. Clin. Res. 21: 661A).

Dr. Hall is a National Heart and Lung Institute Pulmonary Academic Awardee (HL70822).

Received for publication 14 January 1975 and in revised form 26 July 1976.

\section{INTRODUCTION}

Laurell and Eriksson first described in 1963 an association between alpha-1-antitrypsin (AAT) ${ }^{1}$ deficiency and pulmonary emphysema (1). It is now known that serum AAT is inherited in a multiallelic, autosomal, codominant pattern. So far, 23 codominant protease inhibitor (Pi) alleles that determine the amount of circulating serum AAT have been described (2). Approximately $90 \%$ of human subjects have $\mathrm{Pi}$ type $M M$ with levels of alpha-1-antitrypsin of approximately $225 \mathrm{mg} / 100 \mathrm{ml}$. In contrast, subjects with the rare $\mathrm{Pi}$ type $\mathrm{ZZ}$ have serum AAT levels in the order of only $25 \mathrm{mg} / 100 \mathrm{ml}$. This $\mathrm{ZZ}$ state has been unequivocally associated with pulmonary emphysema characterized by onset in early adulthood (3).

The clinical significance of intermediate levels of AAT is currently under intensive investigation. In particular, attention has been focused on individuals with $\mathrm{Pi}$ type $M Z$, who characteristically have only 55-60\% of normal AAT-concentration, and Pi type $M S$, with $80-85 \%$ of normal values (4). The $M Z$ heterozygote state has been estimated to occur in about $2-5 \%$ and the $M S$ in $6-8 \%$ of various normal populations (5). Studies to date have not conclusively established that intermediate deficiency of AAT is an important risk factor in the pathogenesis of chronic obstructive pulmonary disease (COPD). Several factors that may have contributed to varying results have been identified. For example, in many studies, specific Pi typing has not been utilized, and only quantitative determinations of AAT have been used $(6-8)$. It is now known that these simpler tests

\footnotetext{
${ }^{1}$ Abbreviations used in this paper: AAT, alpha-1-antitrypsin; COPD, chronic obstructive pulmonary disease; $\mathrm{Pi}$, protease inhibitor; $R_{3}, R_{9}, R_{R}$, total pulmonary resistance by oscillometric technique at 3 and 9 cycle/s and at resonant frequency; $\hat{V}_{\max }$, maximal expiratory flow rate.
} 
cannot in all cases accurately discriminate $\mathrm{Pi}$ types $M Z$ and $M S$ from $M M$ individuals (9). Additionally, the individuals examined in some studies have been relatives of patients with $\mathrm{Pi}$ type $\mathrm{ZZ},(10)$, and therefore a familial predisposition to COPD other than AAT deficiency may have introduced an unintentional bias $(11,12)$. Several studies of patients with COPD have demonstrated a higher proportion of $M Z$ subjects than in the general population (13). However, it has not been possible to quantitate this risk factor independently from other well-recognized factors, especially cigarette smoking.

To circumvent some of these inherent difficulties, some studies have focused on asymptomatic individuals. Utilizing specialized physiologic techniques, these studies suggest that there are detectable abnormalities of pulmonary function, even in healthy $M Z$ subjects $(10,14)$. However, the samples in these studies have generally included relatives of a ZZ propositus, or have studied predominantly smokers, and therefore may not have adequately isolated AAT deficiency as the sole or predominant risk factor.

This study compares lung function in subjects with $M Z$ and $M S$ Pi types with the findings observed in $M M$ subjects matched for age, sex, and smoking history. To avoid the criticism directed at earlier studies, all subjects were lifelong nonsmokers. They were randomly selected from a population in which the prevalence of intermediate AAT deficiency had been determined. Pi typing was used to identify the heterozygote, and all subjects were studied with pulmonary function tests designed to detect subtle abnormalities in lung mechanics. The data indicate that in the group of asymptomatic nonsmoking subjects the $M Z$ Pi type, but not the $M S$, have demonstrable mechanical abnormalities of pulmonary function.

\section{METHODS}

Populations. 1,000 consecutive patients attending an early disease detection unit (15) were initially studied. From a venous blood sample two tests were performed:

TABLE I

Mean \pm SE Population Characteristics, AAT Determinations, and Pulmonary Function Studies in MM Controls Compared to the Matched MZ and MS Heterozygote Subjects

\begin{tabular}{|c|c|c|c|c|c|c|c|c|}
\hline \multirow{3}{*}{$\begin{array}{l}\text { Parameters } \\
\text { Pi type } \\
\text { Age, yr }\end{array}$} & \multicolumn{8}{|c|}{ Groups } \\
\hline & \multicolumn{2}{|c|}{$M Z$} & \multicolumn{2}{|c|}{$M M$} & \multicolumn{2}{|c|}{ MS } & \multicolumn{2}{|c|}{$M M$} \\
\hline & 47 & $(4)$ & 47 & (4) & 48 & (4) & 46 & (4) \\
\hline Height, $\mathrm{cm}$ & 168 & $(2)$ & 163 & (3) & 168 & (3) & 167 & (3) \\
\hline AAT determination, $m g / 100 \mathrm{ml}$ & 125 & (5) & 205 & (19) & 178 & (7) & 195 & (12) \\
\hline Males/females & \multicolumn{2}{|c|}{$8 / 7$} & \multicolumn{2}{|c|}{$8 / 7$} & \multicolumn{2}{|c|}{$9 / 5$} & \multicolumn{2}{|c|}{$9 / 5$} \\
\hline \multicolumn{9}{|l|}{ Pulmonary function data } \\
\hline $\mathrm{FEV}_{1}, \%$ pred. & 110 & (3) & 107 & (3) & 105 & (3) & 107 & (3) \\
\hline $\mathrm{FEV}_{1} / \mathrm{FVC}, \%$ & 75 & $(1)$ & 74 & $(2)$ & 76 & (1) & 77 & (1) \\
\hline MMEFR, \% pred. & 104 & (5) & 99 & (8) & 102 & (6) & 99 & $(7)$ \\
\hline $\mathrm{S}_{\mathrm{gaw}}, \mathrm{s}^{-1} \mathrm{~cm} \mathrm{H}_{2} \mathrm{O}^{-1}$ & 0.311 & $(0.03)$ & 0.310 & $(0.03)$ & 0.291 & $(0.04)$ & 0.268 & $(0.02)$ \\
\hline TLC, \% pred. & 105 & $(6)$ & 101 & (7) & 102 & (5) & 101 & $(5)$ \\
\hline $\mathrm{RV}, \%$ pred. & 108 & (7) & 94 & (5) & 107 & (6) & 94 & (4) \\
\hline RV/TLC & 0.32 & $(2)$ & 0.33 & (3) & 0.32 & (2) & 0.30 & (1) \\
\hline $\mathrm{D}_{\mathrm{L}}, \%$ pred. & 137 & (6) & 131 & (5) & 128 & (7) & 111 & (3) \\
\hline$\dot{\mathrm{V}}_{75}, s^{-1}$ & 1.08 & $(0.05) \ddagger$ & 1.43 & $(0.05)$ & 1.38 & $(0.05)^{*}$ & 1.47 & $(0.05)$ \\
\hline$\dot{\mathrm{V}}_{50}, s^{-1}$ & 0.60 & $(0.03) \ddagger$ & 0.82 & $(0.04)$ & 0.85 & $(0.04)$ & 0.85 & $(0.04)$ \\
\hline$\ddot{\mathrm{V}}_{25}, s^{-1}$ & 0.28 & $(0.02) \ddagger$ & 0.56 & $(0.03)$ & 0.50 & $(0.05)$ & 0.53 & $(0.06)$ \\
\hline $\mathrm{R}_{3}, \mathrm{~cm} \mathrm{H} \mathrm{H}_{2} \mathrm{O}$ liter $/ \mathrm{s}$ & 2.41 & $(0.12)$ & 2.37 & $(0.13)$ & 2.73 & $(0.18)$ & 2.72 & $(0.21)$ \\
\hline $\mathrm{R}_{\mathrm{R}}, \mathrm{cm} \mathrm{H} \mathrm{H}_{2} \mathrm{O} /$ liter $/ \mathrm{s}$ & 2.18 & $(0.11)$ & 2.24 & $(0.12)$ & 2.64 & $(0.17)$ & 2.56 & $(0.21)$ \\
\hline $\mathrm{R}_{9}, \mathrm{~cm} \mathrm{H}{ }_{2} \mathrm{O} /$ liter $/ \mathrm{s}$ & 1.90 & $(0.12)$ & 2.13 & $(0.12)$ & 2.44 & $(0.16)$ & 2.42 & $(0.20)$ \\
\hline $\mathrm{R}_{3}-\mathrm{R}_{9}$ (FDI), cm H $\mathrm{H}_{2} \mathrm{O} /$ liter $/ \mathrm{s}$ & 0.511 & $(0.045) \downarrow$ & 0.239 & $(0.036)$ & 0.266 & $(0.039)$ & 0.293 & $(0.025)$ \\
\hline $\mathrm{R}_{9} / \mathrm{R}_{3}$ & 0.783 & $(0.022)$ & 0.898 & $(0.015)$ & 0.893 & $(0.015)$ & 0.886 & $(0.01)$ \\
\hline
\end{tabular}

Abbreviations: EID, electroimmunodiffusion; \% pred., percent of normal values drawn from published data (see text); $\mathrm{FEV}_{1}$, forced expiratory volume in $1 \mathrm{~s} ; \mathrm{FVC}$, forced vital capacity; MMEFR, maximal mid-expiratory flow rate; $S_{\text {gaw }}$, specific airway conductance; TLC, total lung capacity; $R V$, residual volume; $D_{L}$, single breath diffusing capacity; $\dot{\mathrm{V}}_{75}, \dot{\mathrm{V}}_{50}, \dot{\mathrm{V}}_{25}$, maximal expiratory flow rate in percent of lung volume seen at 75,50 , and $25 \%$ of vital capacity.

$* P<0.05$ for $M Z-M M$ pairs

$\$ P<0.01$ for $M Z-M M$ pairs 
(a) $\mathrm{Pi}$ typing with acid starch gel and antigen-antibody crossed electrophoresis according to the method of Fagerhol and Laurell $(16,17)$; and $(b)$ quantitative levels of AAT by a modification of the original immunologic procedure of Laurell (17). Details of these methods have been described elsewhere (15). In the present study, $36 \mathrm{MZ}$ subjects and $60 \mathrm{MS}$ subjects were identified. Of these $M Z$ subjects 15 had never smoked cigarettes, cigars, or pipes. For this study, these individuals were matched with consecutive nonsmoking $M M$ controls for sex and age. Of the MS subjects, 24 had never smoked. To construct a study group numerically compatible to the $M Z$ group, 14 consecutively identified nonsmoking $M S$ subjects were matched with appropriate $M M$ controls. Pairs were agematched according to decades. These individuals were asked to return for detailed pulmonary function testing. All of these subjects initially contacted agreed to participate.

Pulmonary function testing. Forced expiratory flow rates were obtained in the standing position with a 13.5liter Stead-Wells spirometer and calculated by methods described by Kory et al. (18). Values were expressed as percent of predicted normal values published by Morris et al. (19). Functional residual capacity and airway resistance were measured in a body plethsmograph $(20,21)$. Single breath carbon monoxide-diffusing capacity was determined by the methods of Ogilvie, et al. (22). Values were expressed as a percentage of normal values published by Bates et al. (23). Maximal expiratory flow volume curves were obtained in all subjects with a Med-Science model 70 spirometer (Med-Science Electronics, Inc., St. Louis, Mo.) whose output was displayed on a cathode ray storage oscilloscope and photographed (24). Maximal flow rates $\left(\dot{\mathrm{V}}_{\max }\right)$ at $75 \%$, $50 \%$, and $25 \%$ of the forced vital capacity maneuver were calculated and the maximal expiratory flow volume curve was plotted from these three points. To correct for differences in the size of subjects, all flow rates were expressed as flow divided by the instantaneous lung volume present at that flow rate $(25)$. Total pulmonary resistance $\left(\mathrm{R}_{\mathrm{T}}\right)$ was measured in all subjects with a modification of the forced oscillometric technique as described by Interiano et al $(26) . R_{T}$ was measured at $3\left(R_{3}\right), 5\left(R_{5}\right), 7\left(R_{7}\right)$, and $9\left(R_{9}\right)$ cycle/s. $R_{T}$ at resonant frequency of the subjects $\left(R_{R}\right)$ was between 5 and 7 cycle/s. Theoretical aspects of this procedure have been described elsewhere $(27,28)$.

Statistical methods. Various flow rates, resistance measurements, and some composites of the resistance measurements, such as $R_{3}-R_{9}$ and $R_{9} / R_{3}$, discussed later, were analyzed by various parametric and nonparametric statistical methods. Several two-sided univariate parametric and nonparametric tests, such as the $t$-test, the Wilcoxon signed rank test, and the sign test (29) were performed on each of the variables. The significance probabilities ( $P$ values) from some of these tests provide measures of the statistica significance of the observed differences between the pulmonary functions of the matched pairs. A number of parametric and nonparametric multivariate tests, such as Hotelling's $\mathrm{T}^{2}$-test (30) and multivariate signed rank tests (31) were also performed on the data and yielded essentially the same conclusions.

\section{RESULTS}

Table I lists the pertinent characteristics of the study population and mean values for pulmonary function measurements. As previously documented, the overall sample from which these subjects were derived closely

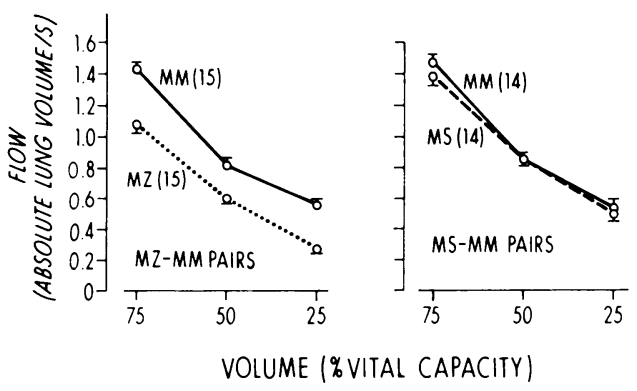

Figure 1 Mean \pm SE maximal expiratory flow rates in $M Z$ and $M S$ heterozygotes compared to $M M$ control subjects. Flow is expressed as a function of absolute lung volume to correct for differences in lung size. Differences in flow rates at $75 \%, 50 \%$, and $25 \%$ of vital capacity are statistically significant $(P<0.01)$ between $M Z$ and $M M$ pairs. No significant differences were present between $M S$ and $M M$ pairs.

reflected the age and sex distribution of metropolitan Rochester, N. Y. (15). None of these individuals participating in the health screen had identifiable respiratory complaints for which they were seeking medical attention. Specifically, respiratory symptoms elicited by the British Medical Research Council Questionnaire were minimal and comparable in each of the phenotype groupings. As might be expected in this group of life-long nonsmokers, none complained of chronic cough or sputum production. Quantitative levels of AAT concentration demonstrated the expected lower mean values for $M S$ and $M Z$ groupings compared to the $M M$ control group.

Residual volume determinations were elevated in both $M S$ and $M Z$ subjects compared to $M M$ controls. Single breath diffusing capacity demonstrated slightly higher values for $M Z$ and $M S$ subjects than $M M$ controls. None of these differences was statistically significant.

Mean maximal expiratory flow volume curves for both pair groupings are displayed in Fig. 1, and are listed in Table I. In addition, complete individual data for each MZ-MM pair are presented in Table II. $M S$ subjects demonstrated lower flow rates at $\dot{V}_{\text {max }}$ $75 \%$, statistically significant compared to $M M$ controls. However, flow rates at $50 \%$ and $25 \%$ of vital capacity were identical in $M S$ and $M M$ pairs. Highly significant differences (Table I) in flow rates at all lung volumes were observed in $M Z-M M$ pairs. $M Z$ subjects demonstrated impaired maximal flow rates at each of the calculated points (Fig. 1).

Total pulmonary resistance by the oscillometric method was measured at $3,5,7$, and 9 cycle/s. No significant differences in airway resistance at any of the frequencies measured were observed between either $M S-M M$ or $M Z-M M$ pairs (Table III). The relationship between oscillatory frequency and resist- 
TABLE II

Maximal Expiratory Flow Rates $\left(\dot{V}_{\max }\right)$ Expressed as Percentage of Absolute Lung Volume at 75\%, 50\%, and $25 \%$ of the

Vital Capacity in Nonsmoking MZ Subjects Compared to MM Controls Matched for Age, Sex, and Smoking History

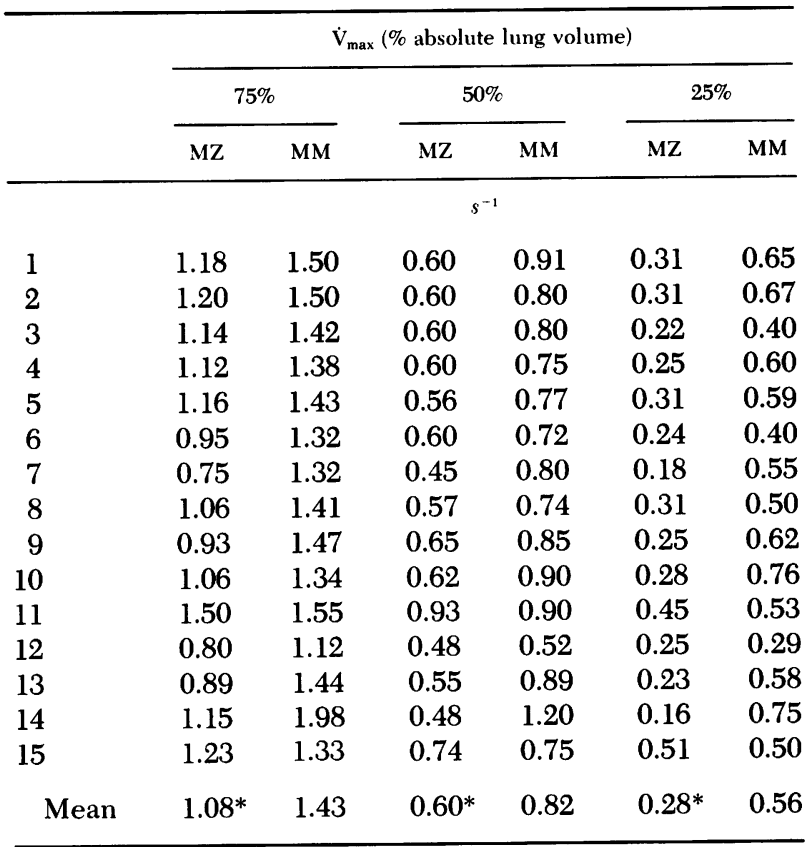

${ }^{*} P<0.01$ for $M Z-M M$ pairs.

ance in a representative $M Z-M M$ matched pair is demonstrated in Fig. 2. Note that at $R_{9}$, values are nearly equal for both subjects, but $R_{3}$ is higher in the $M Z$ subject. The slope of the resultant curve is therefore steeper for the $M Z$ subject compared to his $M M$ control. A simple expression of this slope was derived by subtracting $R_{9}$ from $R_{3}$. In interpreting this "frequency dependence index" (FDI), the higher the resultant numerical value, the greater the degree of frequency dependence of total pulmonary resistance. In addition, the relationship of oscillatory frequency and resistance was analyzed by simply dividing $R_{9}$ by $R_{3}$. In this instance, a steeper slope will produce a lower numerical value. Mean $R_{3}-R_{9}$ values and $R_{9} / R_{3}$ values for $M Z$ subjects were significantly elevated over $M M$ controls, but $M S$ subjects were indistinguishable from $M M$ controls (Table I, Fig. 3).

Fig. 4 demonstrates the relationship between $R_{3}-R_{9}$ and $\dot{V}_{\max }$ at $25 \%$ of vital capacity. A high degree of correlation was obtained. Similar results were observed comparing individual values of $R_{3}-R_{9}$ with $\dot{\mathrm{V}}_{\max }$ at $50 \%$ of vital capacity.

\section{DISCUSSION}

The relationship of intermediate AAT deficiency state to an enhanced risk of pulmonary disease remains controversial. Some studies of AAT phenotype frequencies in groups of patients with COPD have demonstrated an increased incidence of $M Z$ subjects in such populations $(13,32,33)$, but others have not been able to document this correlation $(9,34)$. Another approach has been the study of relatively asymptomatic heterozygote populations as in the present study. Some studies have utilized offspring and siblings of severely deficient subjects with documented lung disease $(10,14)$. This approach is open to the criticism that an observed higher prevalence of pulmonary function abnormalities in these samples could reflect genetic factors other than AAT deficiency $(11,12)$. To avoid this source of bias, the subjects in this study were randomly selected from an

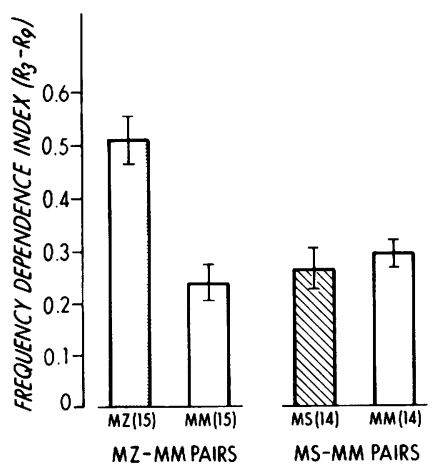

FIGURE 2 Relationship of total pulmonary resistance $\left(R_{T}\right)$ by oscillometrics to frequency of superimposed oscillations measured at $3,5,7$, and 9 cycle/s. Shown are the resultant curves for an $M Z(O)$ subject and matched $M M$ control (๑). Frequency dependence index (FDI) was calculated from the difference between $R_{T}$ at 3 cycle/s and $R_{T}$ at 9 cycle/s $\left(\mathrm{R}_{3}-\mathrm{R}_{9}\right)$. FDI for the $M M$ subject was $2.47-2.38$ or $0.09 \mathrm{~cm} \mathrm{H}_{2} \mathrm{O} / \mathrm{liter} / \mathrm{s}$; for the $M Z$ subject: $3.08-2.46$ or $0.62 \mathrm{~cm} \mathrm{H}_{2} \mathrm{O} /$ liter/s.

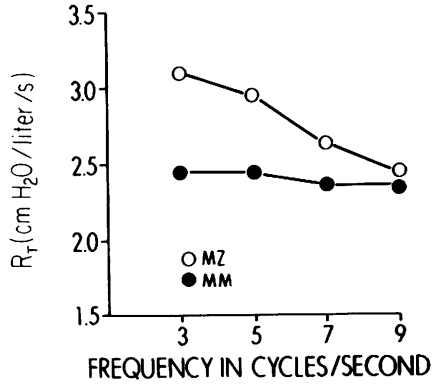

1072

Hall, Hyde, Schwartz, Mudholkar, Webb, Chaubey, and Townes 
TABLE III

Pulmonary Resistances and Resultant Frequency Dependence Index

(FDI) in Nonsmoking MIZ Subjects Compared to MIM

Controls Matched for Age and Sex

\begin{tabular}{|c|c|c|c|c|c|c|c|c|}
\hline \multirow{2}{*}{$\begin{array}{c}\text { Pi type } \\
\text { pair grouping }\end{array}$} & \multicolumn{4}{|c|}{$M Z$} & \multicolumn{4}{|c|}{$M$} \\
\hline & $\mathbf{R}_{3}$ & $\mathbf{R}_{\mathrm{R}}$ & $\mathrm{R}_{8}$ & FDI & $\mathrm{R}_{3}$ & $\mathrm{R}_{\mathrm{R}}$ & $\mathrm{R}_{*}$ & FDI \\
\hline & \multicolumn{4}{|c|}{ ('m H.O/liter/s } & \multicolumn{4}{|c|}{ c'm $\mathrm{H}_{2} \mathrm{O}$ /liter/s } \\
\hline 1 & 2.76 & 2.66 & 2.26 & 0.50 & 3.08 & 2.90 & 2.86 & 0.22 \\
\hline 2 & 2.08 & 1.86 & 1.68 & 0.40 & 2.31 & 2.25 & 2.20 & 0.11 \\
\hline 3 & 2.60 & 2.31 & 2.05 & 0.55 & 2.20 & 2.00 & 1.86 & 0.34 \\
\hline 4 & 2.96 & 2.56 & 2.30 & 0.66 & 3.08 & 2.76 & 2.66 & 0.42 \\
\hline 5 & 3.20 & 2.84 & 2.64 & 0.56 & 2.96 & 2.76 & 2.66 & 0.30 \\
\hline 6 & 2.08 & 1.60 & 1.15 & 0.93 & 2.97 & 2.60 & 2.55 & 0.42 \\
\hline 7 & 3.08 & 2.85 & 2.46 & 0.62 & 2.47 & 2.47 & 2.38 & 0.09 \\
\hline 8 & 2.56 & 2.38 & 2.08 & 0.48 & 2.40 & 2.38 & 2.32 & 0.08 \\
\hline 9 & 1.40 & 1.40 & 1.00 & 0.40 & 1.68 & 1.60 & 1.54 & 0.14 \\
\hline 10 & 2.48 & 2.21 & 2.01 & 0.47 & 2.46 & 2.38 & 2.30 & 0.16 \\
\hline 11 & 2.00 & 1.80 & 1.67 & 0.33 & 1.35 & 1.29 & 1.14 & 0.21 \\
\hline 12 & 2.56 & 2.38 & 2.10 & 0.46 & 2.22 & 2.00 & 1.68 & 0.54 \\
\hline 13 & 2.07 & 1.86 & 1.45 & 0.62 & 2.00 & 1.86 & 1.80 & 0.20 \\
\hline 14 & 2.22 & 2.00 & 1.68 & 0.54 & 2.23 & 2.20 & 2.10 & 0.13 \\
\hline 15 & 2.07 & 2.00 & 1.93 & 0.14 & 2.15 & 2.07 & 1.93 & 0.22 \\
\hline Mean & 2.41 & 2.18 & 1.90 & $0.51^{*}$ & 2.37 & 2.24 & 2.13 & 0.24 \\
\hline
\end{tabular}

$* P<0.01$ for $. M Z-. M$ pairs.

early disease detection unit. This unit differs in at least one important respect from a pure random population, in that some stimulus must have brought these subjects to the detection unit for evaluation. Several indices were monitored to see if this stimulus caused bias. First, it was determined that the population in the detection unit reflected closely the distribution of age, sex, and race of persons living in the metropolitan Rochester, N. Y., area (15). Second, the prevalance of phenotypes was compared to a completely random census tract study of the greater Rochester population (15). Prevalence rates did not differ significantly. For example, in the census tract study $2.3 \%$ of the 930 subjects were the $\mathrm{MZ} \mathrm{Pi}$ type, and $3.3 \%$ of the 1,018 subjects studied in the early disease detection unit were $\mathrm{Pi}$ type MZ. These were not statistically significant differences. These data suggest that the subjects in this study accurately reflected the community at large.

In our present study, and in the previously reported survey from which this sample was derived, measurement of conventional spirometry failed to distinguish intermediate subjects from normals. Similarly, Morse, et al. (8) found in a large population study that intermediate levels of AAT were not associated with any diminution in expiratory flow rates. Determinations of static lung volumes and diffusing capacity demonstrated no clear-cut difference between pair groupings.
It is well recognized that asymptomatic individuals showing normal conventional tests of pulmonary function may have significant degrees of mechanical dysfunction. Our study utilized two rapid, simple methods currently believed capable of detecting early airway obstruction in asymptomatic populations. First, according to some investigators, maximal expiratory flow-volume curves $\left(\dot{\mathrm{V}}_{\max }\right)$, especially if they are corrected for lung volume, can detect early airway obstruction associated with cigarette smoking (25).

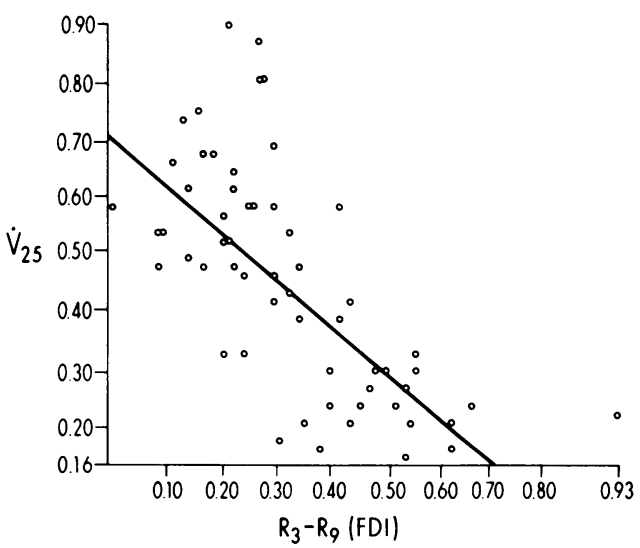

FIGURE 4 Relationship between $\dot{V}_{\max }$ at $25 \%$ vital capacity $\left(\dot{V}_{25}\right)$ and $R_{3}-R_{9}$ (FDI) (see text) for all subjects regardless of AAT Pi type. Heavy line indicates calculated regression line. A correlation coefficient of -0.6769 was observed. 
TABLE IV

Effect of Changes in Compliance of One Lung on Total Pulmonary Resistance at 3 cycles/s $\left(R_{3}\right)$, 9 cycles/s $\left(R_{9}\right)$, and $R_{3}-R_{9}(F D I)$

\begin{tabular}{|c|c|c|c|c|c|}
\hline \multicolumn{3}{|c|}{$\begin{array}{c}\text { Dimension of } \\
\text { "diseased" compartment }\end{array}$} & \multicolumn{3}{|c|}{$\begin{array}{l}\text { Resultant values of } \\
\text { resistance for both lungs }\end{array}$} \\
\hline $\mathrm{C}_{\mathrm{L}}$ & $\mathrm{R}_{\mathrm{A}}$ & $\mathrm{TC}$ & $\mathbf{R}_{3}$ & $\mathrm{R}_{9}$ & FDI \\
\hline liter/cm & cm/liter/s & $s$ & $\mathrm{~cm} / \mathrm{liter} / \mathrm{s}$ & $\mathrm{cm} / \mathrm{liter} / \mathrm{s}$ & $\mathrm{cm} / \mathrm{liter} / \mathrm{s}$ \\
\hline 0.005 & 4 & 0.02 & 3.08 & 2.29 & 0.79 \\
\hline 0.01 & 4 & 0.04 & 2.46 & 2.07 & 0.39 \\
\hline 0.05 & 4 & 0.2 & 2.01 & 2.00 & 0.01 \\
\hline 0.10 & 4 & 0.4 & 2.00 & 2.00 & 0.00 \\
\hline 0.20 & 4 & 0.8 & 2.00 & 2.00 & 0.00 \\
\hline 0.5 & 4 & 2.0 & 2.01 & 2.00 & 0.01 \\
\hline 1.0 & 4 & 4.0 & 2.01 & 2.00 & 0.01 \\
\hline 2.0 & 4 & 8.0 & 2.01 & 2.00 & 0.01 \\
\hline 5.0 & 4 & 20.0 & 2.01 & 2.00 & 0.01 \\
\hline
\end{tabular}

Abbreviations: $\mathrm{C}_{\mathrm{L}}$, lung compliance; $\mathrm{R}_{\mathrm{A}}$, airway resistance; TC, time constant; $F D I=$ frequency dependence index. Note: The other lung of the two compartments has the dimensions of $C_{L}=0.1$ liter $/ \mathrm{cm}, R_{A}=4 \mathrm{~cm} /$ liter per $\mathrm{s}$ and $\mathrm{TC}=0.4 \mathrm{~s}$. Note that only very low compliances cause significant frequency dependence of resistance.

We noted statistically significant diminutions in expiratory flow in $M Z$ subjects. Other investigators, studying nonsmoking $M Z$ relatives of $Z Z$ individuals, have noted similar findings (10).

Second, the development of uneven airway time constants was determined by the technique of measuring total pulmonary resistance at varying frequencies. According to the theoretical work of Otis et al. (35), both the observed airway resistance and lung compliance will fall as the frequency of airflow increases in the presence of asynchronous time constants in the lung. Recent work from our laboratory indicates that frequency dependence of total pulmonary resistance is closely correlated with frequency dependence of dynamic compliance in young adult smokers (36). Several previous studies $(14,37)$ have noted frequency dependence of dynamic compliance in patients with intermediate levels of AAT.

\section{Pathogenesis of mechanical abnormalities in $\mathrm{MZ}$ heterozygotes}

The present data, along with previously published studies, permit some speculation regarding the pathophysiology of intermediate AAT deficiency. In particular the limitation in expiratory flow rates in $M Z$ subjects was highly correlated with the presence of asynchronous time constants as measured by frequency dependence of resistance, suggesting that these two mechanical abnormalities are related to a common pathophysiological mechanism (Fig. 4). Several alternative methods may be proposed.

Regional alterations in lung compliance. The frequency dependence of pulmonary resistance in this study and the frequency dependence of dynamic compliance described by others (14) in $M Z$ subjects are presumably the sequelae of asynchronous time constants explainable by regional alterations in lung compliance. A predilection for basilar involvement has been described in severely deficient homozygous subjects by lung scanning and autopsy examination $(38,39)$. If the same process were present in intermediate deficient subjects, the disease process might exaggerate the gravity-dependent regional differences in time constants present in normal lungs, thus creating true regional asynchronous time constants. Several factors reason against this hypothesis. While Fallat et al. (40) have described delayed clearance of ${ }^{133} \mathrm{Xe}$ from the base of the lungs in intermediate deficient subjects, this finding may be related to smoking, since these regional differences were not observed in nonsmoking intermediate subjects. Moreover, theoretical considerations do not seem to fit this model. Based on the equations of Otis and coworkers (35), the frequency-dependent characteristics of such a two-compartment lung with asynchronous time constants can be analyzed. Compliance of a twocompartment lung must differ by more than 10-fold to produce the observed changes in resistance from 3 to 9 cycle/s noted in our $M Z$ subjects (Table IV). In addition, an alteration in regional compliance of this order of magnitude would likely be associated with other physiologic abnormalities. For example, in pathological studies of homozygotes ( $\mathrm{Pi}$ type ZZ) there is marked pulmonary capillary as well as parenchymal destruction in involved areas of lung (37). Thus, the patients with intermediate deficiency would be expected to have some diminution in diffusing capacity if the disease process has a predilection for the base of the lungs. Such marked regional increases in lung compliance would also be expected to increase residual volume, impair distribution of ventilation, and increase closing volumes. Since these types of abnormalities have only been seen in a small proportion of $M Z$ subjects drawn from a smoking population (10), regional loss of elastic recoil is not a satisfactory explanation for the mild abnormalities found in our nonsmoking $M Z$ subjects.

Generalized loss of lung function. Our data support an alternate pathophysiologic mechanism. Subjects with intermediate AAT deficiency may have generalized rather than regional abnormalities of the structural elements of the lung, causing frequency dependence of resistance and diminished flow rates. 
Mead (41) first pointed out that frequency-dependent behavior of the lungs can be present in the absence of peripheral parenchymal time-constant discrepancies, as described in the classic Otis et al. model (35). He showed that if the lung is divided into two compartments, one containing the central conducting airways with low compliance, and the other containing the more compliant peripheral airways, a rise in peripheral resistance will cause the pattern of frequency dependence of resistance and compliance seen in human disease states. Fig. 5A shows how this model of uneven time constants between conducting airways and lung parenchyma results in frequency dependence of resistance when peripheral airway resistance increases. It also shows that if loss of elastic recoil results in a rise in compliance of the peripheral airways without a rise in peripheral resistance, the resultant increase in airway time constants would not produce frequency dependence of resistance. Alternatively, a rise in compliance of the more central conducting airways will result in frequency dependence of resistance and compliance (Fig. 5B).

These ingenious explanations for frequency dependence of resistance and compliance imply that two basic physiological alterations may cause the frequency dependence of resistance seen in the $M Z$ subjects $(41,42)$. First, there may be a rise in peripheral resistance but not of peripheral compliance. Second, there could be an increase in compliance of the conducting airways such as might result from loss of elastic support or an alteration in the intrinsic properties of these airways. Either mechanism would result in limitation of maximal expiratory flow rates. Currently available data in $M Z$ subjects do not permit a distinction between these two mechanisms.

The hypothesis that mechanical abnormalities in $M Z$ subjects reflect generalized rather than regional abnormalities in lung structure and function is consistent with biochemical data regarding the relationship of AAT and pulmonary emphysema. While there is no direct biochemical evidence linking deficiency of protease inhibitors and human emphysema (43), enzymatic alteration of connective tissue of the lung, particularly elastin, remains a possibility. For example, AAT inhibits human granulocytic proteases, including both an elastase and a collagenase (44). Deficiency of AAT might lead to increased levels of enzymes and destruction of lung tissue.

The clinical significance of these physiologic abnormalities described remains unclear. Prospective studies would be needed to determine if these subjects will eventually develop symptomatic lung disease. Others have recently pointed out that cigarette smoking may be the significant determinant of the development of COPD in $M Z$ heterozygotes $(45,46)$.
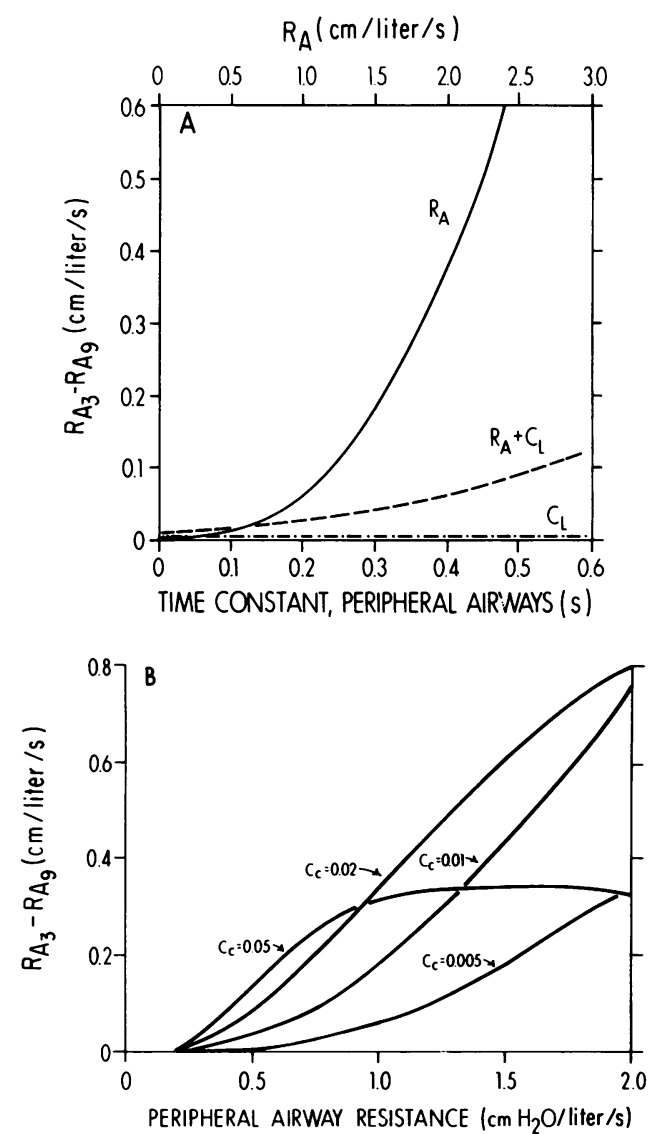

FIGURE 5 A. Theoretical effect of varying the time constant of the peripheral airways on frequency dependence of airway resistance $\left(R_{A}\right)$, recorded as the difference between $\mathbf{R}_{\mathbf{A}}$ measured at 3 cycles/s $\left(\mathbf{R}_{\mathrm{A} 3}\right)$ and at 9 cycles/s $\left(\mathbf{R}_{\mathbf{A} 9}\right)$ $\left(R_{\mathrm{A} 3}-R_{\mathrm{A} 9}\right)$. We assumed, with Mead (41), that the lung had a dead space compartment with $C_{L}=0.005$ liter/cm and $R_{A}=0$, and a normal peripheral airway time constant of $0.1 \mathrm{~s}$ due to $C_{L}$ of 0.2 liter $/ \mathrm{cm}$ and $R_{A}$ of $0.5 \mathrm{~cm} /$ liter per $\mathrm{s}$. The solid curve labeled $R_{A}$ gives the values for $R_{A 3}-R_{A 9}$ if the increase in time constants of the peripheral airways were due only to variations in $R_{A}$ and the dotted line if the changes were due only to varying peripheral airway compliance $\left(C_{L}\right)$. Resistance values across the top of the figure only pertain to the solid curve labeled $R_{A}$. The dashed curve gives the values for $R_{A 3}-R_{A 9}$ if $R_{A}$ and $C_{L}$ equally contributed to alterations in the time constant. Note that only rises in resistance contribute to the development of frequency dependence of resistance. Loss of elastic recoil, causing a rise in compliance without a rise in resistance, would not cause frequency dependence of resistance or compliance. B. Effect of rise in compliance of the conducting airways $\left(\mathrm{C}_{\mathrm{c}}\right)$ on frequency dependence of airway resistance. Curve for $\mathrm{C}_{\mathrm{c}}=0.005 \mathrm{liter} / \mathrm{cm} \mathrm{H}_{2} \mathrm{O}$ is the same curve labeled " $R_{A}$ " in Figure $5 A$. Note that if the compliance of the conducting airways $\left(\mathrm{C}_{c}\right)$ doubles from 0.005 liter/s to 0.01 liter/cm $\mathrm{H}_{2} \mathrm{O}$, frequency dependence of resistance, recorded as $R_{\mathrm{A} 3} / \mathrm{R}_{\mathrm{A} 9}$, approximately doubles. However, if $\mathrm{C}_{c}$ increased to $0.02 \mathrm{liter} / \mathrm{cm} \mathrm{H}_{2} \mathrm{O}$, the change is less pronounced at higher values of resistance. Further increases in $\mathrm{C}_{c}$ to values as high as 0.05 liter/cm $\mathrm{H}_{2} \mathrm{O}$ may result in a decrease in $\mathrm{R}_{\mathrm{A} 3}-\mathrm{R}_{\mathrm{A} 9}$ at high resistance values. 


\section{ACKNOWLEDGMENTS}

This work was supported in part by National Heart and Lung Institute Contract 71-2221.

\section{REFERENCES}

1. Laurell, C.-B., and S. Eriksson. 1963. The electrophoretic $\alpha_{1}$-globulin pattern of serum in $\alpha_{1}$-antitrypsin dedeficiency. Scand. J. Clin. Lab. Invest. 15: 132-140.

2. Fagerhol, M. K. 1972. Genetics of the $\mathrm{Pi}$ system. In Pulmonary Emphysema and Proteolysis. C. Mittman, editor. Academic Press, Inc., New York. 121-138.

3. Kueppers, F. 1971. Alpha-1-antitrypsin: physiology, genetics, pathology. Humangenetik. 11: 177-189.

4. Kueppers, F., and L. F. Black. 1974. $\alpha_{1}$-antitrypsin and its deficiency. Am. Rev. Respir. Dis. 110: 176-194.

5. Fagerhol, M. K. 1969. Quantitative studies on the inherited variants of serum $\alpha_{1}$-antitrypsin. Scand. J. Clin. Lab. Invest. 23: 97-103.

6. Welch, M. H., M. E. Reinecke, J. F. Hammarsten, and C. A. Guenter. 1969. Antitrypsin deficiency in pulmonary disease: the significance of intermediate levels. Ann. Intern. Med. 71: 533-542.

7. Lieberman, J. 1969. Heterozygous and homozygous alpha $_{1}$-antitrypsin deficiency in patients with pulmonary emphysema. N. Engl. J. Med. 281: 279-284.

8. Morse, J. O., M. D. Lebowitz, R. J. Knudson, and B. Burrows. 1975. A community study of the relationof alpha $a_{1}$-antitrypsin levels to obstructive lung disease. N. Engl.J. Med. 292: 278-281.

9. Talamo, R. C., C. E. Langley, B. W. Levine, and H. Kazemi. 1972. Genetic vs. quantitative analysis of

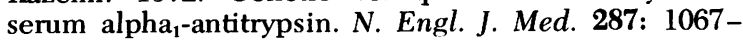
1069.

10. Cooper, D. M., V. Hoeppner, D. Cox, N. Zamel, A. C. Bryan, and H. Levison. 1974. Lung function in alpha antitrypsin heterozygotes (Pi type MZ). Am. Rev. Respir. Dis. 110: 708-715.

11. Larson, R. K., M. L. Barman, F. Kueppers, and H. H. Fudenberg. 1970. Genetic and environmental determinants of chronic obstructive pulmonary disease. Ann. Intern. Med. 72: 627-632.

12. Higgins, M., and J. Keller. 1975. Familial occurrence of chronic respiratory disease and familial resemblance in ventilatory capacity. J. Chronic Dis. 28: 239-251.

13. Barnett, T. B., D. Gottovi, and A. M. Johnson. 1975. Protease inhibitors in chronic obstructive pulmonary disease. Am. Rev. Respir. Dis. 111: 587-593.

14. Ostrow, D. N., and R. M. Cherniack. 1972. The mechanical properties of the lungs in intermediate deficiency of alpha-1-antitrypsin. Am. Rev. Respir. Dis. 106: $377-383$.

15. Webb, D. R., R. W. Hyde, R. H. Schwartz, W. J. Hall, J. J. Condemi, and P. L. Townes. 1973. Serum $\alpha_{1}-$ antitrypsin variants. Prevalence and clinical spirometry. Am. Rev. Respir. Dis. 108: 918-925.

16. Fagerhol, M. K., and C.-B. Laurell. 1970. The Pi system-inherited variants of serum $\alpha_{1}$-antitrypsin. Prog. Med. Genet. 7: 96-111.

17. Laurell, C.-B. 1966. Quantitative estimation of proteins by electrophoresis in agarose gel containing antibodies. Anal. Biochem. 15: 45-52.

18. Kory, R. C., R. Callahan, H. G. Boren, and J. C. Syner. 1961. The Veterans Administration-Army cooperastudy of pulmonary function. I. Clinical spirometry in normal men. Am. J. Med. 30: 243-258.
19. Morris, J. F., A. Koski, and L. C. Johnson. 1971. Spirometric standards for healthy nonsmoking adults. Am. Rev. Respir. Dis. 103: 57-67.

20. DuBois, A. B., S. Y. Botelho, G. N. Bedell, R. Marshall, and J. H. Comroe, Jr. 1956. A rapid plethysmographic method for measuring thoracic gas volume: a comparison with a nitrogen washout method for measuring functional residual capacity in normal subjects. $J$. Clin. Invest. 35: 322-326.

21. DuBois, A. B., S. Y. Botelho, and J. H. Comroe, Jr. 1956. A new method for measuring airway resistance in man using a body plethysmograph: values in normal subjects and in patients with respiratory disease. $J$. Clin. Invest. 35: 327-335.

22. Ogilvie, C. M., R. E. Forster, W. S. Blakemore, and J. W. Morton. 1957. A standardized breath holding technique for the clinical measurement of the diffusing capacity of the lung for carbon monoxide. J. Clin. Invest. 36: 1-17.

23. Bates, D. V., P. T. Macklem, and R. V. Christie. 1971. Respiratory Function in Disease. W. B. Saunders, Philadelphia. 2nd edition. 93-94.

24. Lord, G. P., K. Gazioglu, and N. Kaltreider. 1969. The maximal expiratory flow-volume in the evaluation of patients with lung disease. A comparative study with standard pulmonary function tests. Am. J. Med. 46: 7279.

25. Hyatt, R. E., and L. F. Black. 1973. The flow-volume curve. A current prospective. Am. Rev. Respir. Dis. 107: $191-199$.

26. Interiano, B., R. W. Hyde, M. Hodges, and P. N. Yu. 1973. Interrelation between alterations in pulmonary mechanics and hemodynamics in acute myocardial infarction. J. Clin. Invest. 52: 1994-2006.

27. Grimby, G., T. Takishima, W. Graham, P. Macklem, and J. Mead. 1968. Frequency dependence of flow resistance in patients with obstructive lung disease. J. Clin. Invest. 47: 1455-1465.

28. Goldman, M., R. J. Knudson, J. Mead, N. Peterson, J. R. Schwaber, and M. E. Wohl. 1970. A simplified measurement of respiratory resistance by forced oscillation. J. Appl. Physiol. 28: 113-116.

29. Dixon, W. J., and F. M. Massey, Jr. 1969. Introduction to Statistical Analysis. McGraw-Hill Book Company. New York. 3rd edition. 638 pp.

30. Morrison, D. F. 1967. Multivariate Statistical Methods. McGraw-Hill Book Company, New York. 338 pp.

31. Puri, M. L., and P. K. Sen. 1971. Nonparametric Methods in Multivariate Analysis. John Wiley \& Sons, Inc., New York. 440 pp.

32. Kueppers, F., and A. Dönhardt. 1974. Obstructive lung disease in heterozygotes for alpha-1-antitrypsin deficiency. Ann. Intern. Med. 80: 209-212.

33. Mittman, C., J. Lieberman, and J. Rumsfeld. 1974. Prevalence of abnormal protease inhibitor phenotypes in patients with chronic obstructive lung disease. Am. Rev. Respir. Dis. 109: 295-296.

34. Fagerhol, M. K., and H. E. Hauge. 1969. Serum Pi types in patients with pulmonary diseases. Act a Allergol. 24: $107-114$.

35. Otis, A. B., C. B. McKerrow, R. A. Bartlett, J. Mead, M. B. McIlroy, N. J. Selverstone, and E. P. Radford. 1956. Mechanical factors in distribution of ventilation. J. Appl. Physiol. 8: 427-443.

36. Kjeldgaard, J. M., W. W. Reichert, and R. W. Hyde. 1974. Frequency dependence of total pulmonary resistance in early airway disease. Am. Rev. Respir. Dis. 109: 705-706. (Abstr.).

37. Stevens, P. M., V. S. Hnilica, P. C. Johnson, and R. L. 
Bell. 1971. Pathophysiology of hereditary emphysema. Ann. Intern. Med. 74: 672-680.

38. Greenberg, S. D., D. E. Jenkins, P. M. Stevens, and H. I. Schweppe. 1973. The lungs in homozygous alpha $1^{-}$ antitrypsin deficiency. Am. J. Clin. Pathol. 60: 581592.

39. Stein, P. D., J. D. Leu, M. H. Welch, and C. A. Guenter. 1971. Pathophysiology of the pulmonary circulation in emphysema associated with alpha $\mathrm{a}_{1}$ antitrypsin deficiency. Circulation. 43: 227-239.

40. Fallat, R. J., M. R. Powell, F. Kueppers, and E. Lilker. 1973. ${ }^{133} \mathrm{Xe}$ ventilatory studies on $\alpha_{1}$-antitrypsin deficiency. J. Nucl. Med. 14: 5-13.

41. Mead, J. 1969. Contribution of compliance of airways to frequency-dependent behavior of lungs. J. Appl. Physiol. 26: 670-673.
42. Michaelson, E. D., E. D. Grassman, and W. R. Peters. 1975. Pulmonary mechanics by spectral analysis of forced random noise. J. Clin. Invest. 56: 1210-1230.

43. Hance, A. J., and R. G. Crystal. 1975. The connective tissue of lung. Am. Rev. Respir. Dis. 112: 657-711.

44. Ohlsson, K. 1971. Neutral leukocyte proteases and

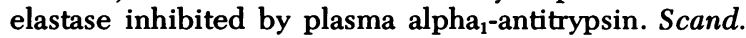
J. Clin. Lab. Invest. 28: 251-253.

45. Mittman, C., J. Lieberman, F. Marasso, and A. Miranda. 1971. Smoking and chronic obstructive lung disease in alpha ${ }_{1}$-antitrypsin deficiency. Chest. 60: 214-221.

46. Klayton, R., R. Fallat, and A. B. Cohen. 1975. Determinants of chronic obstructive pulmonary disease in patients with intermediate levels of alpha ${ }_{1}$-antitrypsin. Am. Rev. Respir. Dis. 112: 71-75. 